\title{
Towards reconstructing the Arctic atmospheric methane history over the 20th century: measurement and modeling results for the NGRIP firn
}

Taku Umezawa ${ }^{1}$, Satoshi Sugawara ${ }^{2}$, Kenji Kawamura ${ }^{3,4,5}$, Ikumi Oyabu ${ }^{3}$, Stephen J. Andrews ${ }^{1,6}$, Takuya

5 Saito $^{1}$, Shuji Aoki ${ }^{7}$ and Takakiyo Nakazawa ${ }^{7}$

${ }^{1}$ National Institute for Environmental Studies, Tsukuba, Japan

${ }^{2}$ Miyagi University of Education, Sendai, Japan

${ }^{3}$ National Institute of Polar Research, Tokyo, Japan

${ }^{4}$ Department of Polar Science, The Graduate University of Advanced Studies (SOKENDAI), Tokyo, Japan

10 Japan Agency for Marine Science and Technology, Yokosuka, Japan

${ }^{6}$ Wolfson Atmospheric Chemistry Laboratories, Department of Chemistry, University of York, York, UK

${ }^{7}$ Center for Atmospheric and Oceanic Studies, Graduate School of Science, Tohoku University, Sendai, Japan

Correspondence to: Taku Umezawa (umezawa.taku@nies.go.jp)

Abstract. Systematic measurements of atmospheric methane $\left(\mathrm{CH}_{4}\right)$ mole fractions at the northern high latitudes only began in

15 the early 1980s, and whilst $\mathrm{CH}_{4}$ measurements from Greenland ice cores covered the period before $\sim 1900$, no reliable observational record is available for the intermediate period. In this study, we reconstruct the atmospheric $\mathrm{CH}_{4}$ for that period, when the mole fraction started to increase rapidly. We use a set of trace gas data measured from firn (an intermediate stage between snow and glacial ice formation) air samples collected at the NGRIP (North Greenland Ice Core Project) site in 2001, in combination with a firn air transport model whose performance is validated by using a set of published firn air data at the

20 NEEM (North Greenland Eemian ice Drilling) site. We examine a variety of possible firn diffusivity profiles using a suite of measured trace gases, and reconstruct the $\mathrm{CH}_{4}$ mole fraction by an iterative dating method. We find that, given the currently available firn air data sets from Greenland, reliable reconstruction of the Arctic $\mathrm{CH}_{4}$ mole fraction is possible only back to the mid 1970s. For the earlier period, it is difficult to identify the atmospheric $\mathrm{CH}_{4}$ history that consistently reproduce the depth profiles of $\mathrm{CH}_{4}$ in firn at both NGRIP and NEEM sites. Therefore, the currently proposed Arctic $\mathrm{CH}_{4}$ history should still be considered preliminary and uncertain, and should not be treated as the known history for constraining firn-air transport models.

\section{Introduction}

Methane $\left(\mathrm{CH}_{4}\right)$ is an important atmospheric greenhouse gas emitted from both natural and anthropogenic sources. Despite great efforts for understanding its global budget, emission estimates of individual sources still have large quantitative uncertainties (e.g. Saunois et al., 2020; Chandra et al., 2021). Anthropogenic activities have enhanced $\mathrm{CH}_{4}$ emissions globally 30 and this resulted in the more than doubled abundance of atmospheric $\mathrm{CH}_{4}$ over the industrial era (e.g. Etheridge et al., 1998). The $\mathrm{CH}_{4}$ emission histories have been estimated based on human activity statistics combined with emission factors (Stern and 
Kaufmann 1996; van Aardenne et al., 2001). Such historical emission inventories have been examined by atmospheric chemistry transport modeling (Houweling et al., 2000; Monteil et al., 2011; Ghosh et al., 2015), in combination with the records of atmospheric $\mathrm{CH}_{4}$ mole fraction reconstructed from polar ice cores (Blunier et al., 1993; Nakazawa et al., 1993; Etheridge et al., 1998; MacFarling Meure et al., 2006; Sapart et al., 2012) and air extracted from porous snow layers at the top of ice sheets (firn) (Francey et al., 1999; Buizert et al., 2012; Sapart et al., 2013).

A large fraction of natural and anthropogenic $\mathrm{CH}_{4}$ sources resides in the northern hemisphere, and thus the atmospheric $\mathrm{CH}_{4}$ trend of the northern hemisphere can provide important information on the evolution of anthropogenic $\mathrm{CH}_{4}$ emissions as well as the variations of natural $\mathrm{CH}_{4}$ emission in response to climatic variability. The interhemispheric gradient of $\mathrm{CH}_{4}$ mole fraction is also key to the allocation of $\mathrm{CH}_{4}$ emissions between both hemispheres (e.g. Dlugokencky et al., 2003; Chandra et al., 2021).

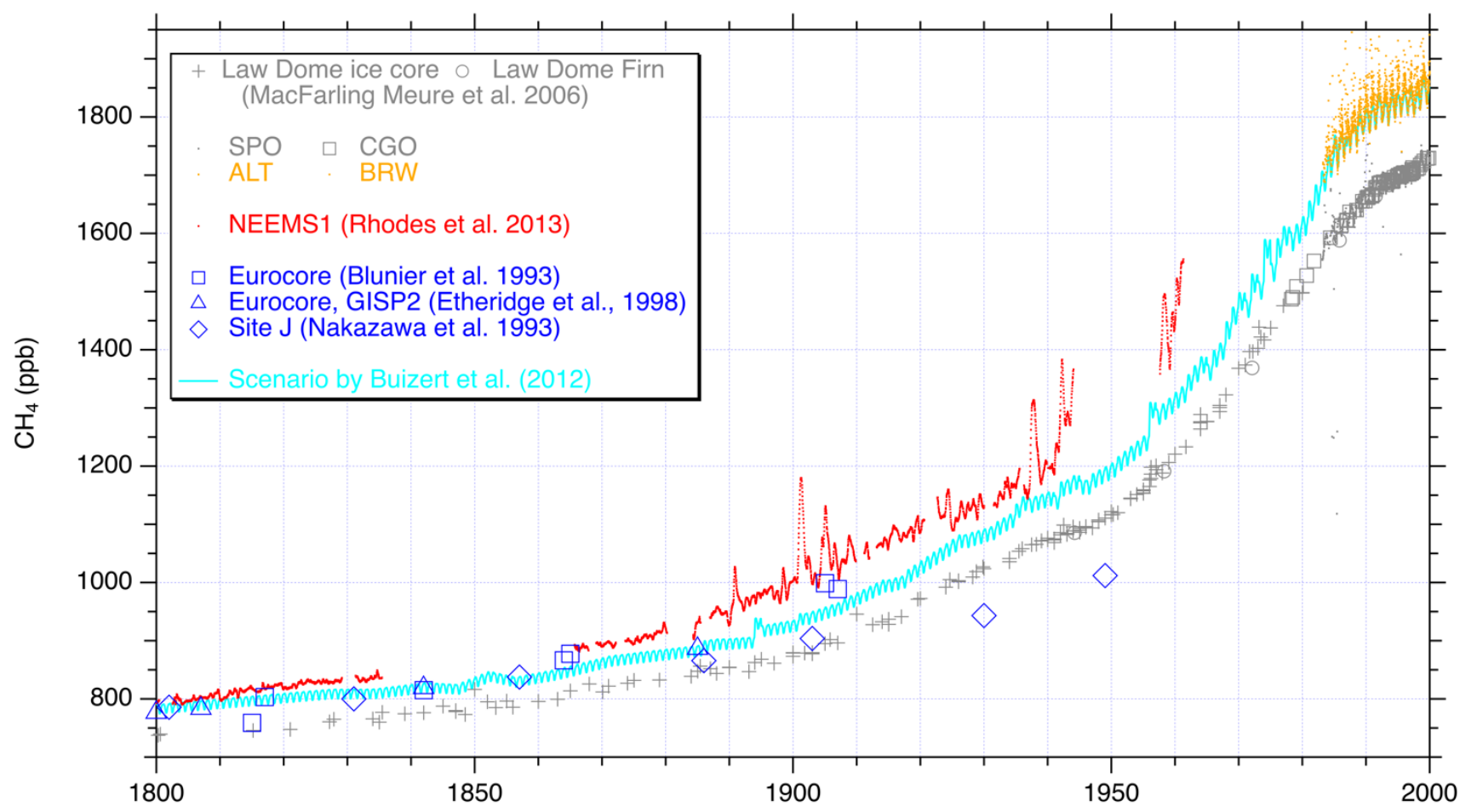

Figure 1: Atmospheric $\mathrm{CH}_{4}$ mole fraction data covering the last 200 years. Symbols in grey are from the southern hemisphere; crosses and open circles are from the Law Dome ice core and firn, respectively (Etheridge et al., 1998; MacFarling Meure et al., 2006); open squares are from Cape Grim (CGO) (MacFarling Meure et al., 2006); dots are from South Pole (SPO) (ftp://aftp.cmdl.noaa.gov/). Colored data from the northern hemisphere; open squares, triangles and diamonds are from the Eurocore (Blunier et al., 1993), Eurocore and GISP2 (Etheridge et al., 1998) and Site J (Nakazawa et al., 1993) ice cores; red dots are the NEEM-S1 ice core (Rhodes et al., 2013); orange dots are from Alert, Canada (ALT) and Barrow, Alaska (BRW) (ftp://aftp.cmdl.noaa.gov/); light blue line is the atmospheric scenario prepared for the NEEM firn modeling (Buizert et al., 2012). 
Systematic measurements of atmospheric $\mathrm{CH}_{4}$ mole fraction began in the 1980s. In Figure 1, $\mathrm{CH}_{4}$ measurements at two Arctic sites Barrow, Alaska (BRW) and Alert, Canada (ALT) are shown (orange dots), whose records start in 1983 and 1985, respectively (data provided by National Oceanic and Atmospheric Administration/Earth System Research Laboratory/Global Monitoring Laboratory, NOAA/ESRL/GML). Although some sparse data from the 1970s are available (e.g. Rice et al., 2016), such "direct" measurements provide $\mathrm{CH}_{4}$ data only since around 1980, which means that some reconstruction methodology is required to infer atmospheric $\mathrm{CH}_{4}$ mole fraction variations before that. For this purpose, air extracted from ice cores and firn layers has been measured. Figure 1 also presents $\mathrm{CH}_{4}$ mole fractions analyzed in ice cores from Greenland (open blue symbols), such as Eurocore (Blunier et al., 1993), Eurocore and GISP2 (Greenland Ice Sheet Project 2) (Etheridge et al., 1998) and Site J (Nakazawa et al., 1993). These data show fairly good agreements with each other until $\sim 1900$, after which the number of

60 data and the consistency among the records are poor. Continuous measurements from NEEM-S1 ice core (Rhodes et al., 2013) presented $\mathrm{CH}_{4}$ mole fractions before $\sim 1960$ (red in Figure 1), but their data are notably higher than the ice core data after $\sim 1850$. Therefore, the data gap between $\sim 1900$ and $\sim 1980$ is not covered reliably either by direct observations or ice core reconstructions.

In comparison to these data, higher-resolution $\mathrm{CH}_{4}$ data are available from Antarctica (grey in Figure 1). The comprehensive

65 Law Dome ice core and firn data set (Etheridge et al., 1998; MacFarling Meure et al., 2006) almost continuously covers the last 200 years and are well connected to the direct measurements at South Pole (SPO, data provided by NOAA/ESRL/GML) and Cape Grim (CGO) (Etheridge et al., 1998; MacFarling Meure et al., 2006). Such consistency and continuity among the datasets suggests that the Antarctic $\mathrm{CH}_{4}$ data can serve as a good reference to represent the global atmospheric $\mathrm{CH}_{4}$ trend over the past centuries. Buizert et al., (2012) used the Antarctic $\mathrm{CH}_{4}$ trend with presumed interpolar difference (IPD) to propose the

$70 \mathrm{CH}_{4}$ history over Greenland (light blue in Figure 1), which in turn was used to constrain the gas diffusivity profile in firn at the North Greenland Eemian ice Drilling (NEEM) site. In their study, the Arctic $\mathrm{CH}_{4}$ scenario was constructed by adding IPD to the Law Dome data, where the IPD was assumed to be proportionally correlated with the growth rate of $\mathrm{CH}_{4}$. This seems reasonable assumption, given that the IPD and growth rate are both largely subject to changes in emissions from the northern hemisphere (Dlugokencky et al., 2003; Chandra et al., 2021). The Arctic $\mathrm{CH}_{4}$ scenario by Buizert et al. (2012) is consistent

75 with the direct measurements that started in the 1980s, and ice core reconstructions before $\sim 1900$ (Figure 1). It is thus considered as the most likely synthetic atmospheric $\mathrm{CH}_{4}$ trend for the northern high latitudes, and is treated as a "known" history, by which the diffusivity profiles in firn are tuned in firn-air transport models (Witrant et al., 2012; Trudinger et al., 2013). It is however noted that this scenario has not been validated against independent estimates for the data gap period (from $\sim 1900$ to 1980 ).

80 In this study, we present a set of mole fractions of $\mathrm{CH}_{4}$ and other trace gases in firn air samples collected at the North Greenland Ice Core Project (NGRIP) site. Using the atmospheric scenarios by Buizert et al. (2012), we simulate the depth profiles of trace gases in the NGRIP firn with our firn-air transport model. We examine a variety of modeling cases for different diffusivity profiles and reconstruct the Arctic atmospheric $\mathrm{CH}_{4}$ over the late 20th century using the iterative dating approach (Trudinger 
et al., 2002). The reconstructed $\mathrm{CH}_{4}$ trend is evaluated by comparison to the original atmospheric $\mathrm{CH}_{4}$ scenario and to the

\section{Experimental method}

Firn air was sampled at the Greenland site NGRIP $\left(75^{\circ} 10^{\prime} \mathrm{N}, 42^{\circ} 32^{\prime} \mathrm{W}, 2959 \mathrm{~m}\right.$ AMSL) in May-June 2001. Accumulation, surface density, mean temperature and pressure are $179 \mathrm{~kg} \mathrm{~m}^{-2} \mathrm{yr}^{-1}, 300 \mathrm{~kg} \mathrm{~m}^{-3}, 241 \mathrm{~K}$ and $680 \mathrm{hPa}$, respectively. Details of the firn and firn-air sampling have been described elsewhere (Kawamura et al., 2006; Ishijima et al., 2007). At the NGRIP site, two shallow holes (EU and Japanese holes) were drilled (Kawamura et al., 2006; Landais et al., 2006), and the present data are from the firn air samples collected from the Japanese hole. The total number of air-sampling depths is 24 .

Since the technical details are reported in Kawamura et al. (2021), only brief descriptions of relevant data presented in this study are given here. $\mathrm{CH}_{4}$ mole fractions of the firn air samples were measured using a gas chromatograph (Agilent 6890, Agilent Technologies Inc.) equipped with a flame ionization detector (GC-FID) at Tohoku University (TU), with a reproducibility of $2 \mathrm{ppb}$ (Umezawa et al., 2014). The $\mathrm{CH}_{4}$ mole fractions were determined against our working standard gases that were calibrated on the TU1987 $\mathrm{CH}_{4}$ scale (Aoki et al., 1992; Umezawa et al., 2014; Fujita et al., 2018). The difference between the TU1987 $\mathrm{CH}_{4}$ scale and the $\mathrm{WMO} \mathrm{CH}_{4}$ mole fraction scale (on which the $\mathrm{NEEM} \mathrm{CH}_{4}$ data were measured) is estimated to be $\sim 0.5 \mathrm{ppb}$ at the current atmospheric $\mathrm{CH}_{4}$ levels (Fujita et al., 2018). Oyabu et al. (2020) reported that ice core data analyzed on the TU1987 and WMO scales showed good agreement within analytical uncertainties, indicating consistency of both scales, including for the lower mole fractions (e.g. $\sim 700 \mathrm{ppb}$ ). It is therefore likely that the difference between both scales is well below the variations of interest in this study, and thus no correction is applied for use of the NGRIP and NEEM firn data.

The firn air samples were measured for $\mathrm{CO}_{2}$ and $\mathrm{SF}_{6}$ mole fractions respectively by using a nondispersive infrared gas analyzer (NDIR) and a gas chromatograph equipped with an electron capture detector (GC-ECD) at TU. The measurement reproducibility is estimated to be $0.02 \mathrm{ppm}$ for $\mathrm{CO}_{2}$ and $0.09 \mathrm{ppt}$ for $\mathrm{SF}_{6}$ and mole fractions of both gases are reported on the TU2010 $\mathrm{CO}_{2}$ and TU2002 $\mathrm{SF}_{6}$ scales, respectively (Sugawara et al., 2018).

The NGRIP firn air samples were also analyzed for selected halocarbons (CFC-11, CFC-12, CFC-113 and $\mathrm{CH}_{3} \mathrm{CCl}_{3}$ ) on the Vacuum Preconcentration and Refocusing-Gas Chromatography-Mass Spectrometry (VPR-GCMS) system, which was developed based on the work by Saito et al. (2006). An aliquot of the sample was transferred into an evacuated canister of $\sim 0.3$

$110 \mathrm{~L}$ at around ambient pressure $(\sim 100 \mathrm{kPa})$ and the inner pressure of the canister was recorded. The air is extracted by a vacuum pump through a preconcentration trap filled with HayeSep D cooled to $-135^{\circ} \mathrm{C}$ using a Stirling cooler. The preconcentration trap was heated to $-70^{\circ} \mathrm{C}$ to release major atmospheric constituents and then up to $100^{\circ} \mathrm{C}$ to transfer the trapped compounds to a cryofocusing trap containing Carboxene 1000 /Tenax TA at $-100^{\circ} \mathrm{C}$. The trap was then heated to $180^{\circ} \mathrm{C}$ to inject the trapped gases onto a PoraBOND Q separation column for subsequent analysis on MS. Mole fractions of individual halocarbons 
115 are determined against a working standard gas (compressed dry air) that was calibrated against synthetic standards on the NIES-08 scales.

\section{Firn air transport model}

Since the gas diffusivity in firn layers is significantly lower than in the atmosphere, the movements of atmospheric constituents are driven mostly by molecular diffusion according to their vertical mole fraction gradients under the influence of gravity. In general, lighter air components (or isotopologues) diffuse faster under their mole fraction gradients, while heavier components accumulate in the deeper layers due to the gravitational effect. Hence the depth profiles of trace gas mole fractions in firn are determined by the atmospheric histories transferred towards depth in the firn by the molecular diffusion driven by the mole fraction gradient and gravity. At the bottom of firn, the air is trapped as bubbles in the ice sheet, which creates slow downward motion of firn air.

125 The firn column can be divided into three zones: a convective zone (CZ), a diffusive zone (DZ) and a lock-in zone (LIZ) (Sowers et al., 1992; Kawamura et al., 2006; Buizert et al., 2012). In CZ, primarily driven by surface winds and fluctuations of atmospheric pressure, air is mixed with the overlying atmosphere (Sowers et al., 1992; Kawamura et al., 2006). The CZ thickness at NGRIP is estimated to be below $2 \mathrm{~m}$ (Kawamura et al., 2006). In DZ, which is sufficiently isolated from the surface turbulence, movement of air is governed by molecular diffusion. Gravitational enrichment according to the barometric equation (i.e. linear increases of $\delta^{15} \mathrm{~N}$ of $\mathrm{N}_{2}$ and $\delta^{18} \mathrm{O}$ of $\mathrm{O}_{2}$ ) occurs with depth, which stops at the top of LIZ (Sowers et al., 1992; Schwander et al., 1993; Kawamura et al., 2006). The top of LIZ (lock-in depth) at NGRIP is at depth 63 m (Kawamura et al., 2006). In LIZ, advection with the enclosing ice matrix dominates the transport of air, and air parcels are gradually isolated as bubbles. Traditionally, it was supposed that high-density impermeable ice layers stop diffusivity in LIZ completely, however, recent studies demonstrated finite diffusivity in LIZ (Severinghaus et al., 2010; Buizert et al., 2012; Trudinger et al.,

135 2013). The deepest air sampling at NGRIP was successfully made at $77.71 \mathrm{~m}$, and total pore closure is considered in the deeper layers in our modeling.

\subsection{Modeling firn air transport}

We use a one-dimensional diffusion model that has been used for the reconstruction of isotope ratios of $\mathrm{CO}_{2}$ and $\mathrm{N}_{2} \mathrm{O}$ (Sugawara et al., 2003; Ishijima et al., 2007). The model is conceptually similar to that developed by Trudinger et al. (1997);

140 it is based on a theoretical formation of diffusion (Schwander et al., 1993) and a bubble trapping process (Rommelaere et al., 1997). Air movement in the firn is driven by molecular diffusion and a gravitational effect. Namely, a trace gas flux in firn is expressed by

$F=-D\left\{s \frac{\partial}{\partial z}\left(\frac{c}{s}\right)-\frac{m g c}{R T}\right\}$ 
where $D$ is the effective diffusivity of a trace gas molecule, the variables $s, c$, and $T$ are open porosity, trace gas molar concentration, and firn temperature, respectively, and the constants $m, g$, and $R$ are the mass number of the trace gas, the acceleration of gravity, and the gas constant, respectively. Vertical advection flux of the trace gas, caused by air trapping at the close-off zone and downward bulk motion of firn, is expressed by using the equation given by Rommelaere et al. (1997). Conservation of the trace gas is given by

$\frac{\partial c}{\partial t}+\frac{\partial(v c)}{\partial z}+\frac{\partial F}{\partial z}+r c=0$

for the open pore space and

$\frac{\partial c_{b}}{\partial t}+\frac{\partial\left(v_{f} c_{b}\right)}{\partial z}-r c=0$,

for bubbles. Here $c$ and $c b$ are trace gas molar concentrations in the open pore space and bubbles, respectively. Vertical speed of air in the open pore space $v$ is distinguished from that of firn itself $v_{f}$. The vertical speed of firn $v_{f}(z)$ is simply given by dividing the accumulation rate by the firn density under the assumption of the steady-state densification of firn. At the transition zone where the open pore air is gradually trapped into bubbles, mass conservation is given by using a bubble trapping rate $r$ $\left(\mathrm{s}^{-1}\right)$, which simply means that a portion of the trace gas molar concentration in the open pore space $(r c)$ is added to bubbles. The bubble trapping rate is given as a function of the open porosity, the total porosity, and the vertical speed of firn itself (Rommelaere et al., 1997). The total porosity was calculated from the firn density data. At the transition zone, the total porosity should be divided into the open and closed porosity. The closed porosity $s_{c}$ was calculated by the empirical equation given by

Schawander (1989).

\subsection{Effective diffusivity}

We follow the previous firn-air studies in which the effective diffusivity in firn is optimized with an iterative method so as to minimize the difference between the simulated and observed depth profiles of $\mathrm{CO}_{2}$ (Sugawara et al., 2003; Ishijima et al., 2007). An initial guess of the effective diffusivity for $\mathrm{CO}_{2}, D_{\text {init }}(z)$, was calculated by:

$D_{\text {init }}(z)=D_{0}\left(\frac{T}{253}\right)^{1.85}\left(\frac{1013}{p}\right)\{1.7 s(z)-0.2\}$,

where $s(z)$ and $D_{0}$ represent the open porosity at a depth $z$ and the diffusion coefficient of $\mathrm{CO}_{2}$ at $253 \mathrm{~K}$ and $1013 \mathrm{hPa}$, respectively. $D_{0}$ was set to $1.247 \times 10^{-5}\left(\mathrm{~m}^{2} \mathrm{~s}^{-1}\right)$ according to Trudinger et al. (1997). The bulk density was determined by measuring the dimension and weight of cylindrically cut firn core samples (Kawamura et al., 2006). The effective diffusivity of $\mathrm{CO}_{2}$ thus obtained was converted to those of other trace gases by multiplying by scaling factors from Buizert et al. (2012).

170 Therefore, the depth profile pattern of the effective diffusivity is identical among all gases, but the magnitude is gas-dependent due to the scaling factors. In this study, the effective diffusivity profile prepared for the NGRIP firn by Ishijima et al. (2007) is modified to improve the reproducibility of our newly measured trace gas profiles (section 4). 
https://doi.org/10.5194/acp-2021-736

Preprint. Discussion started: 31 August 2021

(c) Author(s) 2021. CC BY 4.0 License.

(c) (i)

\subsection{Performance of the firn air transport model}

To validate our firn air transport model, we simulated depth profiles of various trace gases in the NEEM firn. Our model did

175 not participate in the model intercomparison study using the NEEM data (Buizert et al., 2012). In this simulation, we employed the atmospheric scenarios prepared by Buizert et al. (2012) as per their model intercomparison. The diffusivity profile optimized for the CIC (Center for Ice and Climate, Niels Bohr Institute, University of Copenhagen) model was tuned for our model. The simulated depth profiles of various compounds are presented in Figure 2 and compared with those by other models presented in Buizert et al. (2012). The results confirm that performance of our model is comparable to those by other groups.

180 As a measure of the model performance, Buizert et al. (2012) compared root mean square deviation (RMSD) between the model and data, which ranged from 0.73 to 0.92 for the six participating models. Following the same approach, our model yields the RMSD value of 0.83 of for the NEEM EU borehole. 

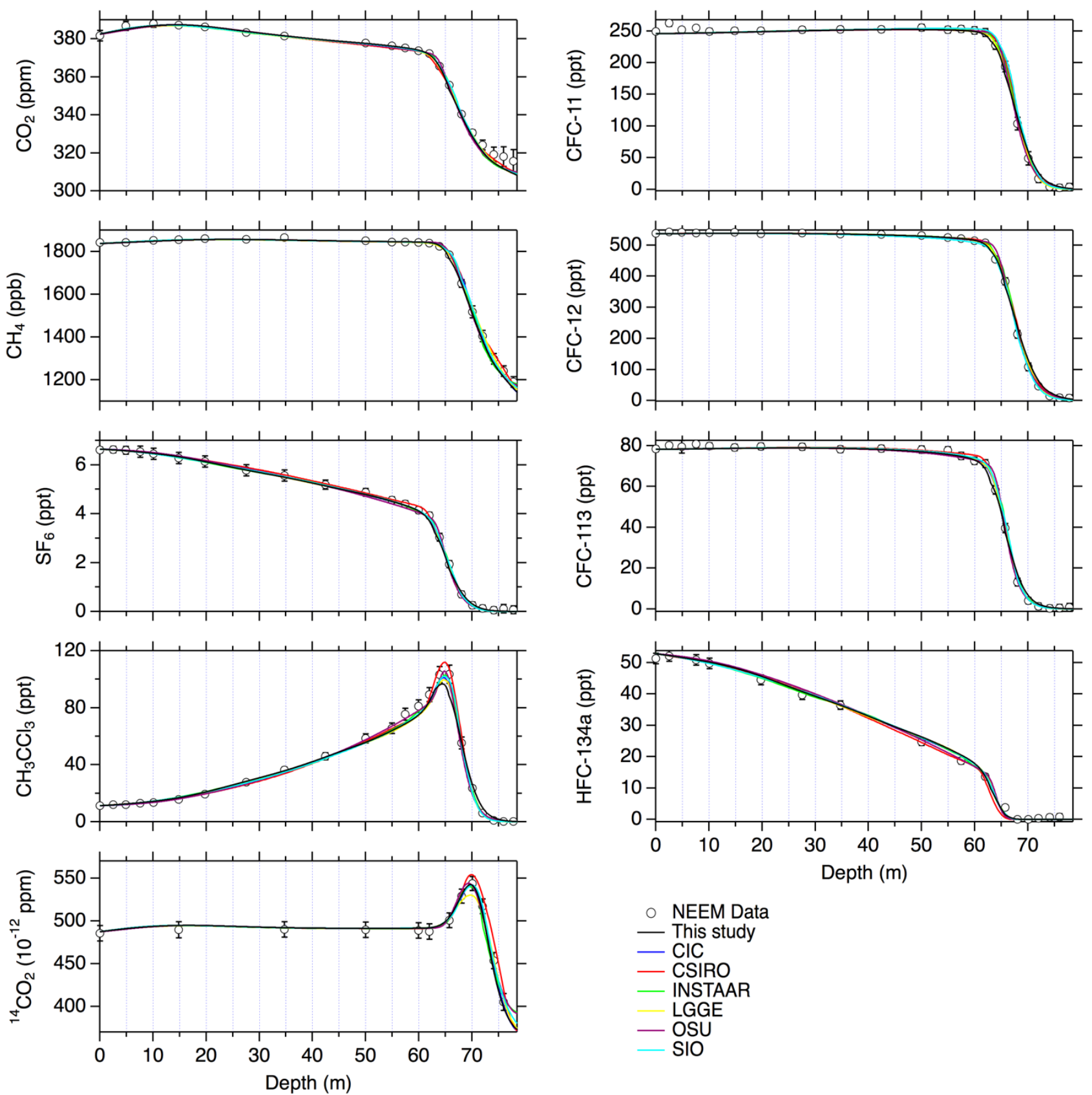

185 Figure 2: Modeled depth profiles of various compounds in the NEEM firn. Open circles in black are the observed data with uncertainty estimated by Buizert et al. (2012). Our model results are shown in black solid lines and results from other models are in colors. Different models are labeled by institutions according to Buizert et al. (2012): CIC (Centre for Ice and Climate), CSIRO (Commonwealth Scientific and Industrial Research Organization), INSTAAR (Institute of Arctic and Alpine Research), LGGE (Laboratoire de Glaciologie et Géophysique de l'Environnement), OSU (Oregon State University) and SIO (Scripps Institution of Oceanography). 


\subsection{Modeling procedure}

Our modeling procedure for reconstructing the atmospheric histories of trace gases was as follows:

(1) To represent atmospheric trace gas trends in the Arctic region, we began by employing atmospheric scenarios prepared for

195 the NEEM firn air modeling (Buizert et al., 2012) for all the trace gases presented in this study $\left(\mathrm{CH}_{4}, \mathrm{CO}_{2}, \mathrm{SF}\right.$, $\mathrm{CFC}-11$, CFC-

12, CFC-113 and $\mathrm{CH}_{3} \mathrm{CCl}_{3}$ ). The firn transport model calculates depth profiles of these trace gases in the NGRIP firn with the initial effective diffusivity described in section 3.2.

(2) We examined the different sets of diffusivity profiles so as to improve overall reproducibility of the modeled profiles of the six trace gases except $\mathrm{CH}_{4}$. In other words, we regarded these six trace gases as constraints to the diffusivity profile. Note that this step assumes that the atmospheric histories of the six gases are known with sufficient accuracy to infer a range of acceptable diffusivity profiles that reproduce the depth profiles of the firn air composition. We prepared 100 different sets of modified diffusivity profiles, and the overall model-data agreement for each set was evaluated based on the RMSD of the six gases.

(3) We ran the model with the 100 different sets of diffusivity profiles to calculate the depth profile of $\mathrm{CH}_{4}$. Note that, based

205 on the earlier steps, we know the diffusivity profiles that generate reasonable firn-air profiles for the six trace gases. Every diffusivity profile was used in combination with the firn-air $\mathrm{CH}_{4}$ data for reconstructing an atmospheric $\mathrm{CH}_{4}$ history. We employed an iterative dating approach (Trudinger et al., 2002) where the initial atmospheric scenario was modified to improve model reproducibility of the $\mathrm{CH}_{4}$ depth profile (see below). The corrected atmospheric $\mathrm{CH}_{4}$ scenarios were then compared to the initial scenario for further discussion.

210 The iterative dating for $\mathrm{CH}_{4}$ was performed as follows:

(1) Depth profile of $\mathrm{CH}_{4}$ was calculated with the initial atmospheric $\mathrm{CH}_{4}$ scenario.

(2) Effective age at each sampling depth was calculated so that the modeled $\mathrm{CH}_{4}$ mole fraction, at that depth, agreed with a value in the atmospheric $\mathrm{CH}_{4}$ scenario.

(3) A new atmospheric $\mathrm{CH}_{4}$ scenario was constructed by assigning the observed $\mathrm{CH}_{4}$ mole fraction, at each depth, to the 215 effective age.

(4) Depth profile of $\mathrm{CH}_{4}$ was again calculated with the revised atmospheric $\mathrm{CH}_{4}$ scenario.

(5) The above steps $2-4$ were repeated until the model-data difference converged within an acceptable range (typically after a few iterations) (Trudinger et al., 2002; Ishijima et al., 2007). In this study, we made five iterations for each modified diffusivity case as we confirmed sufficient convergence of the result. 
https://doi.org/10.5194/acp-2021-736

Preprint. Discussion started: 31 August 2021

(c) Author(s) 2021. CC BY 4.0 License.

(c) (1)

\section{Result}

\subsection{Initial and modified diffusivity simulations}

Figure 3 presents the initial simulation results in comparison to the observed profiles for the six trace gases $\left(\mathrm{CO}_{2}, \mathrm{SF}_{6}, \mathrm{CFC}_{\text {- }}\right.$ 11, CFC-12, $\mathrm{CFC}-113$ and $\mathrm{CH}_{3} \mathrm{CCl}_{3}$ ). As seen in this figure, measured profiles of these trace gases (except $\mathrm{CH}_{3} \mathrm{CCl}_{3}$ ) show gradual decreases with depth in the $\mathrm{DZ}$ and sharp decreases in the LIZ. In contrast, $\mathrm{CH}_{3} \mathrm{CCl}_{3}$ increases with depth in the DZ 225 and sharply decreases in the LIZ. The difference of the depth profile pattern among species is due to their different historical atmospheric trends. It is known that the atmospheric mole fractions of the five trace gases $\left(\mathrm{CO}_{2}, \mathrm{SF}_{6}, \mathrm{CFC}-11, \mathrm{CFC}-12\right.$ and CFC-113) have increased monotonically since the mid 20th century (Sturrock et al., 2002; Martinerie et al., 2009). In contrast, $\mathrm{CH}_{3} \mathrm{CCl}_{3}$ has increased until the early 1990s and has decreased since then (Sturrock et al., 2002; Rigby et al., 2017). Our simulation reproduces the observed depth profiles of these six trace gases in the NGRIP firn fairly accurately with the 230 atmospheric scenarios prepared for modeling the NEEM firn air (Buizert et al., 2012). 

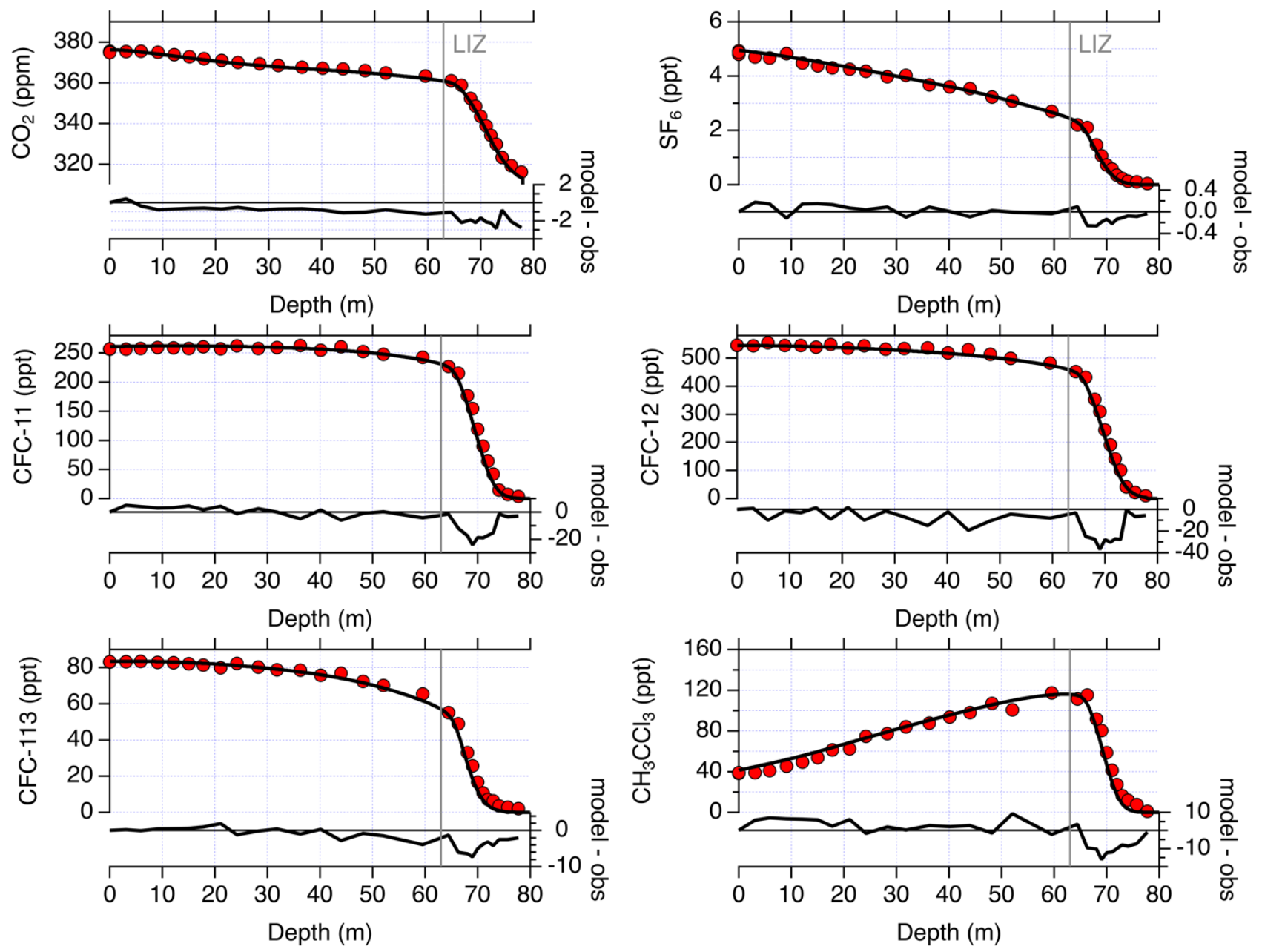

Figure 3: Depth profiles of $\mathrm{CO}_{2}, \mathrm{SF}_{6}, \mathrm{CFC}-11, \mathrm{CFC}-12, \mathrm{CFC}-113$ and $\mathrm{CH}_{3} \mathrm{CCl}_{3}$ in the NGRIP firn. The measurement and model results are shown by red circles and black solid lines, respectively (left axis). The measurement uncertainties are shown as vertical error bars though in many cases they are smaller than the circle sizes. The model-data differences are also shown (right axis). The vertical solid line in each panel indicates the upper depth of LIZ.

It is interesting to note that the depth profiles of $\mathrm{CH}_{3} \mathrm{CCl}_{3}$ at NGRIP and NEEM are remarkably different. Whereas the NEEM data show a relatively sharp $\mathrm{CH}_{3} \mathrm{CCl}_{3}$ peak in the LIZ ( $\sim 5 \mathrm{~m}$, Figure 2), NGRIP does not show such a narrow peak. This is due to the timing of firn air sampling i.e. 2001 for NGRIP and 2008 for NEEM. When the NGRIP firn air was sampled, the signal of the maximum atmospheric $\mathrm{CH}_{3} \mathrm{CCl}_{3}$ in the early 1990s had only reached near the top of the $\mathrm{LIZ}$ at the site, thereby formulating the relatively gentle changes at the shallower depths. On the other hand, seven years later at the NEEM site, such signal was found deeper in the LIZ where the age of air changes rapidly with depth in both deeper and shallower sides. We emphasize that, despite the differences in the depth profiles of $\mathrm{CH}_{3} \mathrm{CCl}_{3}$ at the two sites, our simulations reproduce both profiles measured at both sites well, using the same atmospheric $\mathrm{CH}_{3} \mathrm{CCl}_{3}$ scenario. 
Figure 3 shows that the model-data difference increases in the LIZ for all the trace gases. In particular, the model-data difference is pronounced as a dip around $70 \mathrm{~m}$ for all trace gases, implying that the mismatches may originate in a common factor in the modeling e.g. depth profile of diffusivity. To examine the impact of diffusivity modification on the simulated depth profiles and their agreements with the data, we prepared 100 sets of modified diffusivity profiles (Figure 4). The various diffusivity profiles were constructed by modifying the original profile at certain range of depths in a stepwise manner. Although this simple method does not guarantee identification of a best-match profile, we are confident that an acceptable range of the diffusivity profile is satisfactorily constrained. To reduce the model-data difference in the LIZ (Figure 3), we found that the diffusivity needs to be increased in the shallower layers than the top LIZ i.e. 50-65 m. The diffusivity was also modified in the deeper layers (>65 m) and simulations were made accordingly.
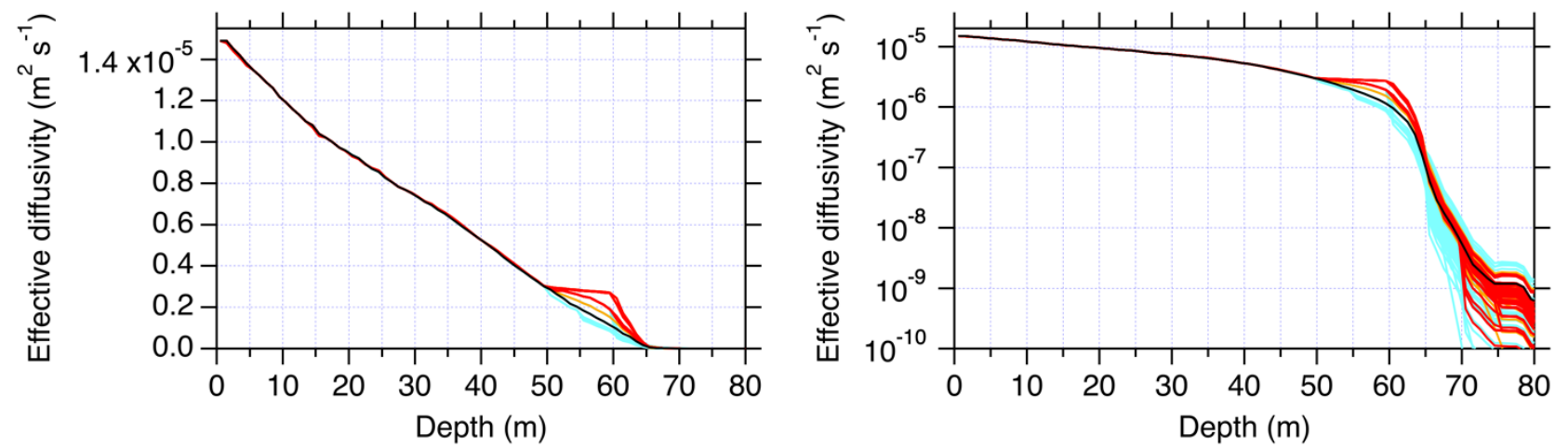

Figure 4: The 100 sets of effective diffusivity profile of $\mathrm{CO}_{2}$ in the NGRIP firn (colored, left panel on a linear scale and right panel on a log scale). The original diffusivity profile is shown in black. See text for colors of the modified diffusivity profiles.

260 The simulated profiles for depths deeper than $50 \mathrm{~m}$ using the 100 diffusivity profiles are presented for the six trace gases (Figure 5). In this figure, the modeling results with the modified diffusivity profiles are shown in colors on the left axis, and the model-data differences of the respective cases are plotted on the right axis. It is clear that the model-data differences could be significantly reduced with some diffusivity cases. We calculated RMSD in the same manner as Buizert et al. (2012) with the measurement uncertainties of $0.2 \mathrm{ppm}$ for $\mathrm{CO}_{2}, 0.2 \mathrm{ppt}$ for $\mathrm{SF}_{6}, 1.1 \mathrm{ppt}$ for CFC-11, $3.3 \mathrm{ppt}$ for CFC-12, 0.6 ppt for CFC-

265113 and $3.2 \mathrm{ppt}$ for $\mathrm{CH}_{3} \mathrm{CCl}_{3}$. The RMSD values are as little as 0.51 for a particular case. In Figure 4 and following figures, the model results with a RMSD of $<0.75$ and $<1.0$ are colored red and orange, respectively, and other cases are colored light blue. 

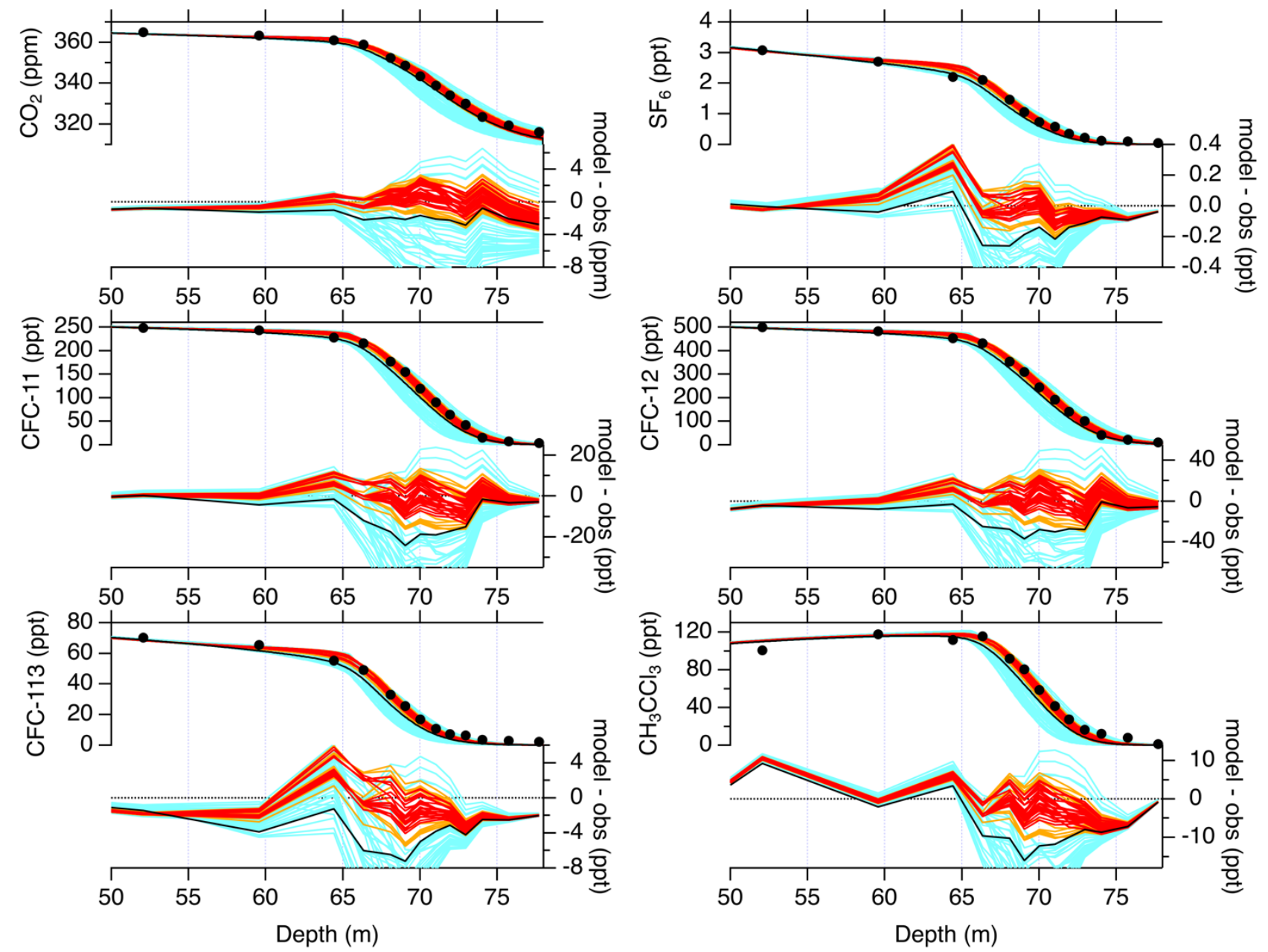

Figure 5: Depth profiles of the six trace gases below $50 \mathrm{~m}$ depth in the NGRIP firn. Black circles indicate the measurements and solid lines in colors are the model results with different diffusivity profiles (left axis). Black lines are modeled results with the initial diffusivity. Also shown are the model-data differences (right axis). See text for difference in line colors.

Likewise, depth profiles of $\mathrm{CH}_{4}$ are shown in Figure 6. These calculations were made with the 100 diffusivity profiles and the atmospheric $\mathrm{CH}_{4}$ scenario for the NEEM firn-air modeling (Buizert et al., 2012). It is interesting to note that the characteristics of the model-data difference for $\mathrm{CH}_{4}$ are different from those for the other six trace gases. For the other trace gases (Figure 5), the initial simulation showed increased model-data differences around $70 \mathrm{~m}$, and they were reduced with some modified diffusivity profiles. For $\mathrm{CH}_{4}$, the model run with the original diffusivity profile reproduces the observed $\mathrm{CH}_{4}$ profile quite well down to $\sim 73 \mathrm{~m}$, but significantly overestimates by $>20 \mathrm{ppb}$ for the lowest three depths (the black solid line). Using the modified diffusivity profiles that allowed better agreements for the other six trace gases (orange and red lines), we actually find larger model-data $\mathrm{CH}_{4}$ difference than in the initial simulation. 


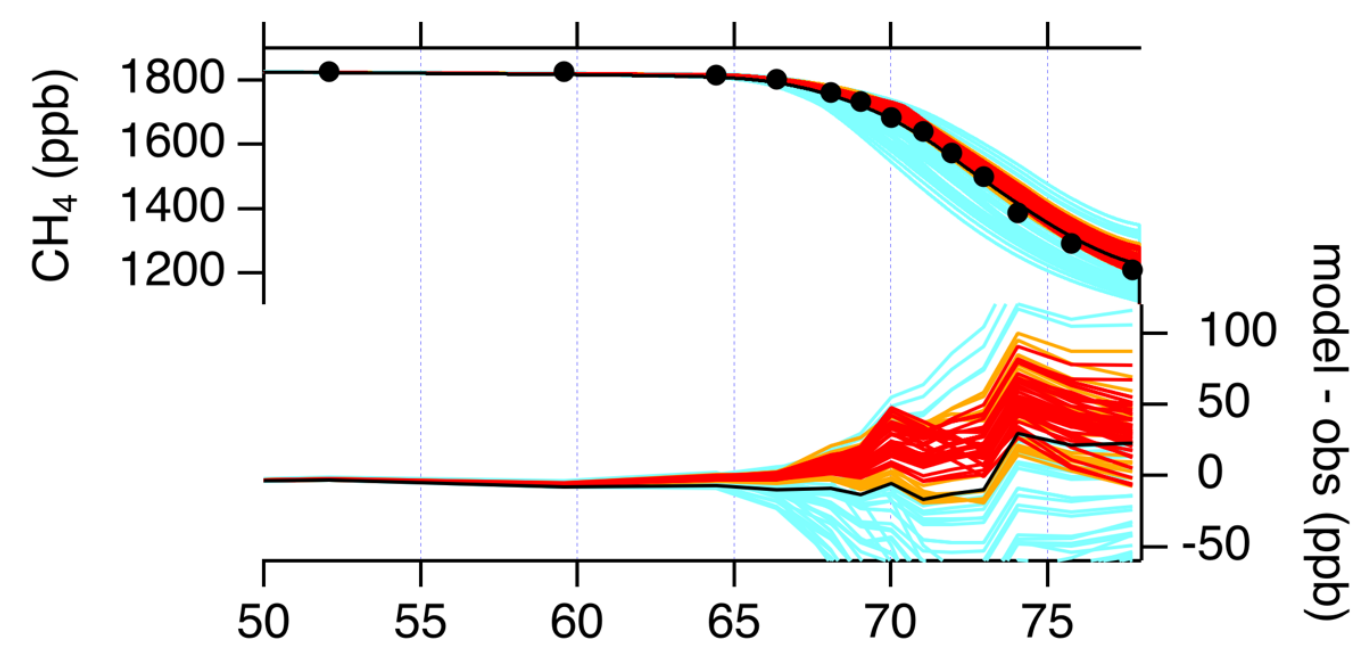

Figure 6: Same as Figure 5, but for $\mathrm{CH}_{4}$.

\subsection{Reconstruction by iterative dating}

We explore the possibility of reconstructing the Arctic $\mathrm{CH}_{4}$ mole fractions by the iterative dating method. This approach sets the diffusivity profile fixed (assumed to be correct) and aims to find an acceptable atmospheric history to reproduce the firnair depth profile. It is considered that the modified diffusivity profiles with the low RMSD values for the six trace gases are adequately evaluated and that the model-data mismatch in the $\mathrm{CH}_{4}$ modeling is therefore attributable to uncertainty in the atmospheric $\mathrm{CH}_{4}$ scenario. The atmospheric $\mathrm{CH}_{4}$ scenarios obtained by the iterative dating method are presented in Figure 7 for the 100 modeling cases of the modified diffusivity. The different simulation cases are colored in the same manner as in the earlier figures (Figures 4-6). Note that the reconstruction cases colored in light blue are considered to be less likely, due to poorer reproduction of the depth profiles (Figures 5 and 6). The model results in red and orange are in good agreement with the initial atmospheric scenario by Buizert et al. (2012) after around 1980. For the earlier period, however, the upper bounds of the reconstructions matches with the initial scenario, and the overall range of acceptable histories is below the initial atmospheric $\mathrm{CH}_{4}$ scenario (circles and shades in red and orange), suggesting that the $\mathrm{CH}_{4}$ mole fractions may have been lower than the initial modeling scenario. 


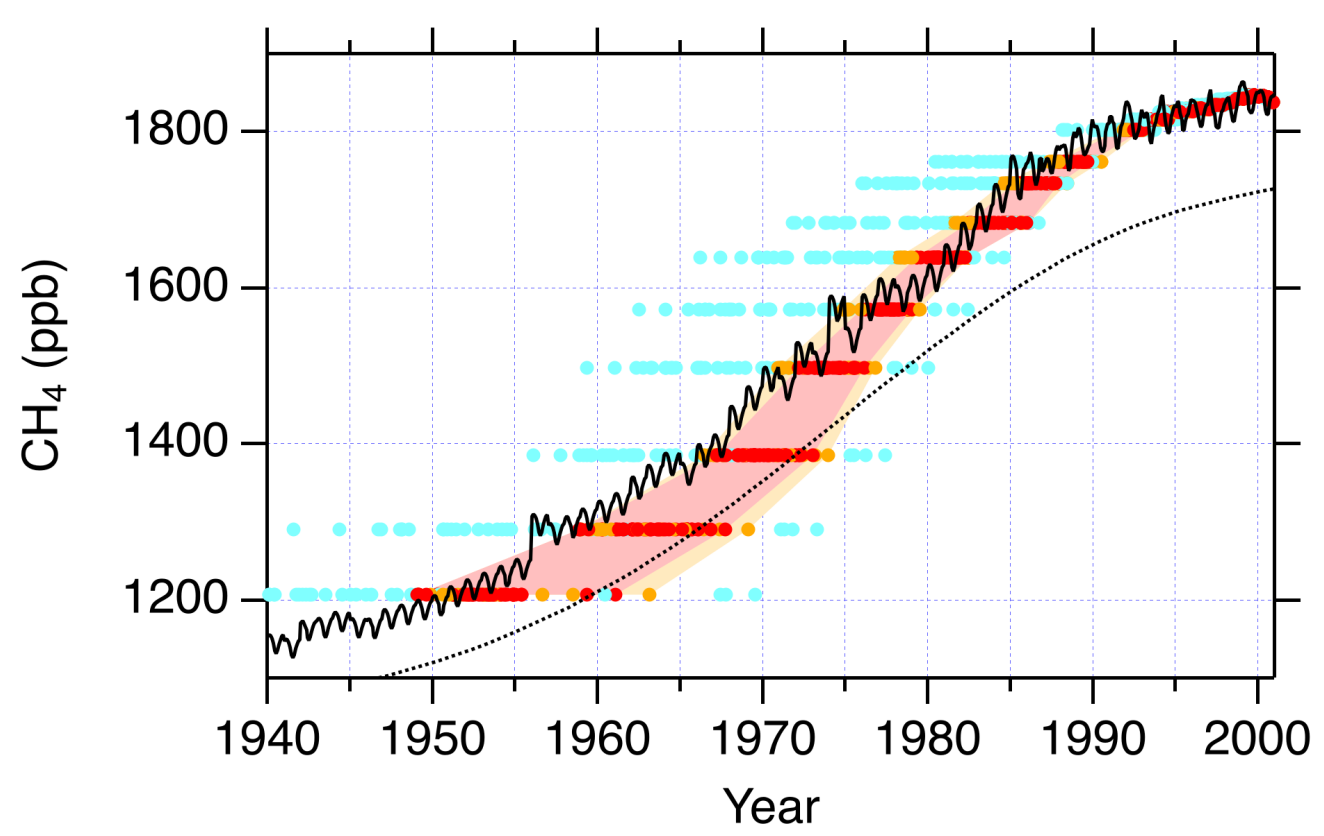

Figure 7: Results of reconstructions by the iterative dating method from the NGRIP firn air (colored circles) for the model cases with the 100 different diffusivity profiles (colored in the same manner as in Figures 5 and 6). The orange and red shades indicate the range of $\mathrm{CH}_{4}$ mole fraction trends reconstructed using the diffusivity profiles that better reproduce the other six trace gases. Black solid line is the initial atmospheric $\mathrm{CH}_{4}$ scenario (Buizert et al., 2012), and black dotted line is the smoothed Antarctic $\mathrm{CH}_{4}$ mole fraction (spline curve) from the Antarctic data shown in Figure 1.

It should be stressed that the reconstructions for the time period before 1980 rely on the $\mathrm{CH}_{4}$ data from the lowest three depths of the NGRIP firn air. The differences between the initial and corrected atmospheric $\mathrm{CH}_{4}$ scenario from these three deepest data are up to $\sim 100 \mathrm{ppb}$. As seen in Figure 7, such reduction in the Arctic atmospheric $\mathrm{CH}_{4}$ scenario over the period would result in alignment with the atmospheric $\mathrm{CH}_{4}$ trend in Antarctica inferred from the Law Dome and other datasets (black dotted line). It is again noted that all the reconstruction cases colored in orange and red used diffusivity profiles that yield relatively good model reproducibility with RMSD values of $<1.0$ and 0.75 , respectively. It is therefore seen that iterative dating-based reconstruction from the NGRIP firn data suggests decreased $\mathrm{CH}_{4}$ mole fraction from the 1950s to 1970s in any case, albeit with large uncertainty.

\subsection{Comparison to the NEEM profile}

To further evaluate consistency of the atmospheric $\mathrm{CH}_{4}$ scenario reconstructed from the NGRIP firn, we ran the model for the NEEM firn using the corrected atmospheric $\mathrm{CH}_{4}$ histories obtained from the iterative dating approach. The modeling results with the initial and modified atmospheric $\mathrm{CH}_{4}$ histories are shown in Figure 8. With the initial scenario (black line), the modeldata difference was $<25 \mathrm{ppb}$, with relatively large differences appearing in the LIZ ( $>63 \mathrm{~m}$ ). However, when the atmospheric 
$\mathrm{CH}_{4}$ histories reconstructed from the NGRIP firn were employed, the reconstruction cases based on the improved reproducibility for the NGRIP firn (orange and red lines) resulted in larger model-data differences of $>50 \mathrm{ppb}$ in the LIZ.

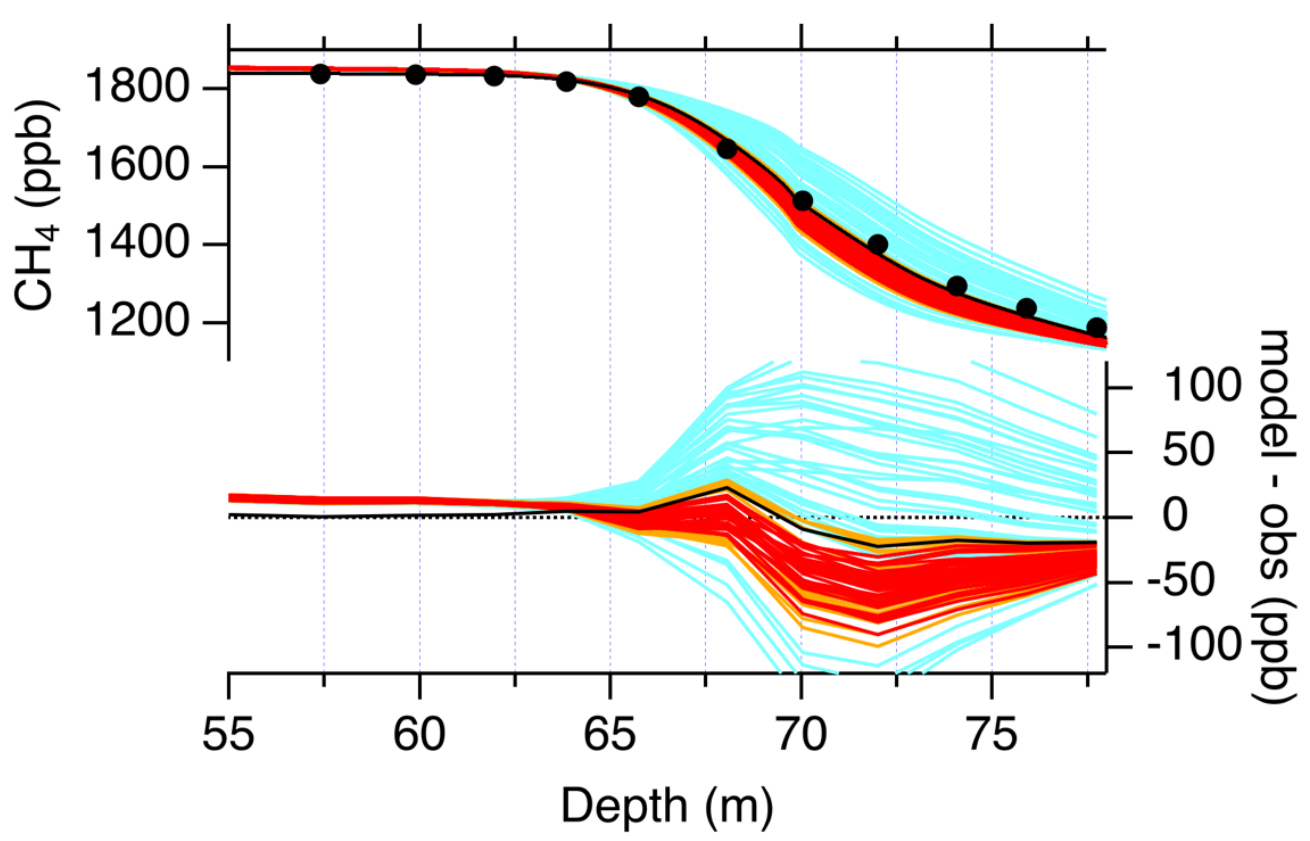

325 Figure 8: Depth profiles of $\mathrm{CH}_{4}$ mole fraction in the NEEM firn at depths below $55 \mathrm{~m}$. The measurements are shown by solid black circles. The modeling results with the atmospheric $\mathrm{CH}_{4}$ scenario by Buizert et al. (2012) and with the $\mathrm{CH}_{4}$ histories estimated from the NGRIP reconstruction are shown by black and colored lines, respectively (left axis). Corresponding model-data differences are also shown (right axis).

\section{Discussion and conclusion}

In section 4, we have shown that, with the atmospheric scenarios prepared for the NEEM firn, depth profiles of $\mathrm{CO}_{2}, \mathrm{SF}_{6}$, CFC-11, $\mathrm{CFC}-12, \mathrm{CFC}-113$ and $\mathrm{CH}_{3} \mathrm{CCl}_{3}$ in the NGRIP firn are accurately reproduced by using the modified diffusivity profiles (Figure 5). This suggests that the atmospheric scenarios of these trace gases used in the modeling are consistent with the depth profiles observed at both firn sites in Greenland (NEEM and NGRIP). In contrast, the observed $\mathrm{CH}_{4}$ profile in the

335 NGRIP firn was not reconciled using the atmospheric scenario prepared for the NEEM firn and the diffusivity profiles that allow adequate reproducibility for the above six trace gases. This suggests either that the Arctic atmospheric scenario of $\mathrm{CH}_{4}$ is uncertain or that the diffusivity profile of the NGRIP firn is underconstrained.

We explored the correction of the atmospheric scenario of $\mathrm{CH}_{4}$ by the iterative dating approach. This method improves agreement to the observed $\mathrm{CH}_{4}$ depth profile in the NGRIP firn, with an implicit assumption that the diffusivity profile in each case is correct. Although uncertainty due to the under-constrained diffusivity profile in the LIZ is large, this attempt suggested 
that the $\mathrm{CH}_{4}$ mole fractions over the period 1950-1980 could be decreased in comparison to the original scenario prepared for the NEEM modeling (Figure 7). However, the follow-up modeling with the corrected atmospheric $\mathrm{CH}_{4}$ histories by the iterative dating based on the NGRIP data did not show improved reproducibility for the $\mathrm{CH}_{4}$ profile at the NEEM site (Figure 8). It is therefore implied that neither the original $\mathrm{CH}_{4}$ scenario by Buizert et al. (2012) nor the corrected $\mathrm{CH}_{4}$ histories by this study, are well validated against the available two Greenland firn data sets (NGRIP and NEEM). The decrease of up to $100 \mathrm{ppb}$ from the original scenario over the period 1950-1980, as suggested by the iterative dating in this study, would make the $\mathrm{CH}_{4} \mathrm{~mole}$ fraction as low as that in Antarctica (Figure 7). We point out that such a nearly-zero IPD of the $\mathrm{CH}_{4}$ mole fraction is highly unlikely, given that major fraction of both natural and anthropogenic $\mathrm{CH}_{4}$ sources resides in the northern hemisphere in both preindustrial and industrial periods (Houweling et al., 2000; Ghosh et al., 2015; Saunois et al., 2020; Chandra et al., 2021).

It is important to note that the reconstructions for the period before 1980 were heaviliy influenced by the three deepest data in the LIZ ( $>74 \mathrm{~m}$ ). Figure 9 shows distributions of the effective age of $\mathrm{CH}_{4}$ at depths below $55 \mathrm{~m}$ in the NGRIP firn, colored the same as in the earlier figures. In addition, the spread of the effective age ( $\left.\sigma_{\text {age }}\right)$ at each sampling depth is shown on the right axis. This figure shows that firn air samples collected at the three lowest sampling depths have effective ages corresponding to the period from $\sim 1950$ to the mid 1970s. In addition, even the acceptable diffusivities yield the spread of the effective age of $>5$ years at those depths (red and orange). This shows that the reconstruction of the $\mathrm{CH}_{4}$ mole fraction for the period is subject to much uncertainty in effective age. The Antarctic atmospheric $\mathrm{CH}_{4}$ record (see Figures 1 and 7) indicates that the atmospheric increase rate of $\mathrm{CH}_{4}$ was $10-15 \mathrm{ppb} \mathrm{yr}^{-1}$ over the period. The 5-year uncertainty in the age estimate for the NGRIP firn air samples could therefore be translated to an uncertainty of $>50 \mathrm{ppb}$ in the Arctic atmospheric $\mathrm{CH}_{4}$ level. This is comparable to the IPD of $\mathrm{CH}_{4}$ mole fraction during the 1950s to 1970s, which was assumed when Buizert et al. (2012) prepared the Arctic atmospheric $\mathrm{CH}_{4}$ scenario for the NEEM modeling. 


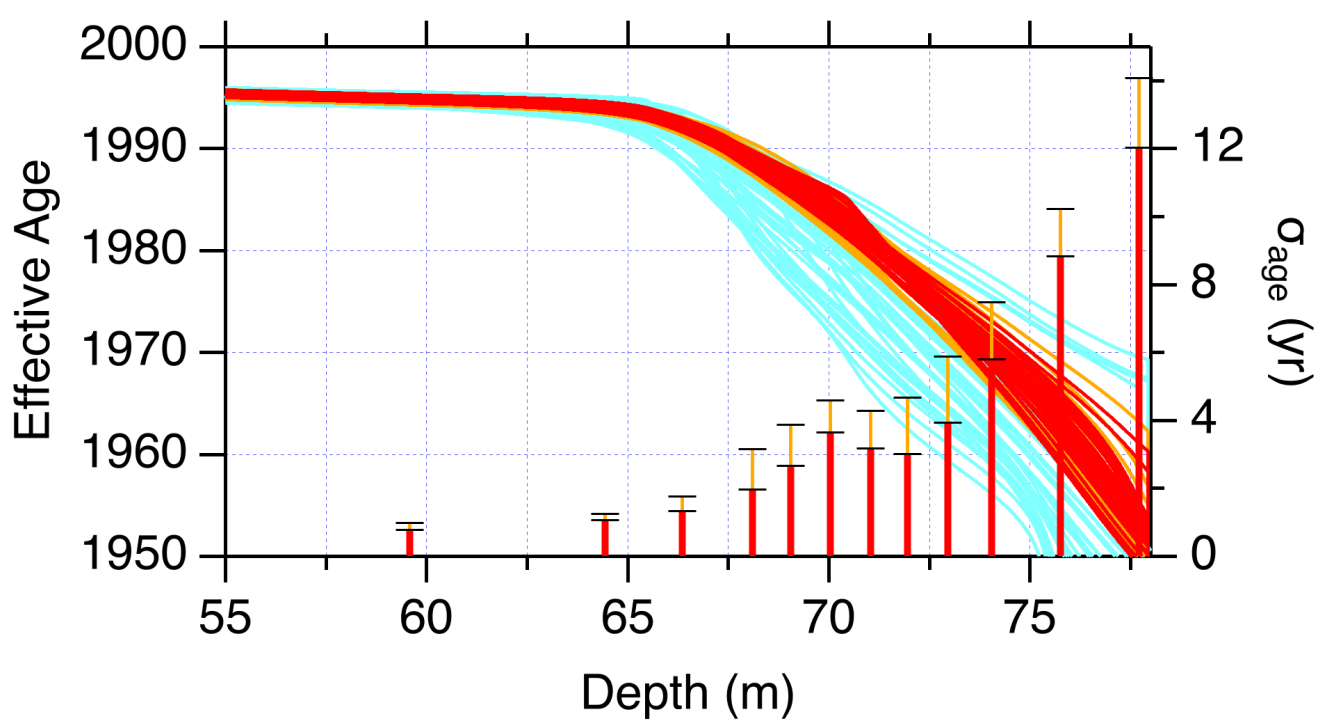

Figure 9: Depth profiles of effective age of $\mathrm{CH}_{4}$ calculated after the iterative dating calculations for depths below $55 \mathrm{~m}$ (left axis). The solid lines represent cases for different diffusivity profiles and are colored in the same manner as in Figures 4-8. Vertical orange and red bars indicate spread of the effective age (maximum minus minimum) at the individual sampling depths among the modeling cases.

The IPD of the atmospheric $\mathrm{CH}_{4}$ mole fraction is important for better understanding the evolution of the global $\mathrm{CH}_{4}$ budget. Given that the Antarctic ice core and firn measurements have provided relatively reliable $\mathrm{CH}_{4}$ records over the 20th century, improved reconstructions from Greenland ice cores and firn air should better constrain the changes in the IPD. To sufficiently constrain the historical global $\mathrm{CH}_{4}$ budget, the reconstruction for Greenland needs to be accurate within $\sim 10 \mathrm{ppb}$, corresponding to $\sim 30 \mathrm{Tg} \mathrm{CH}_{4} \mathrm{yr}^{-1}$ global emission. Unfortunately, based on the firn $\mathrm{CH}_{4}$ data from NGRIP and NEEM, this study demonstrated that consistent reconstruction of the Arctic $\mathrm{CH}_{4}$ mole fraction is achievable only back to the mid 1970s, and that the uncertainty of reconstruction is still very large (around $50 \mathrm{ppb}$ ) for the 1950s to 1970s.

Previous studies have used $\mathrm{CH}_{4}$ as one of tracers that constrain diffusivity profiles in firn (Witrant et al., 2012; Trudinger et al., 2013). These studies have shown that $\mathrm{CH}_{4}$ effectively contributed to constraining diffusivity for deep layers i.e. LIZ in the NEEM firn. However, the use of $\mathrm{CH}_{4}$ as a strong constraint is valid only when its atmospheric scenario given as input to the models was assumed to be correct. Figures 5 and 6 show a larger spread in the model-data differences of $\mathrm{CH}_{4}$ among the different diffusivity cases spread widely in the deepest layers of the LIZ, in comparison to the other six gases. This fact highlights that subtle changes of the diffusivity profile in the $\mathrm{LIZ}$ have a large impact on simulating $\mathrm{CH}_{4}$, and it indeed indicates that the species could serve as an effective diffusivity constraint, if its atmospheric scenario was correctly given with low uncertainty. Although the currently proposed Arctic $\mathrm{CH}_{4}$ history (Buizert et al., 2012) appears a useful choice in firn modeling at Greenland sites, it should be kept in mind that the use of $\mathrm{CH}_{4}$ as a tuning tracer could lead to overfitting of the diffusivity profile. 
Sapart et al. (2013) examined the reconstruction of stable carbon isotope ratio $\left(\delta^{13} \mathrm{C}\right)$ of atmospheric $\mathrm{CH}_{4}$ using firn air measurements from both northern and southern hemispheres. They concluded that, with the available firn measurements and understanding of firn air transport, it is difficult to reliably reconstruct the past trend of $\delta^{13} \mathrm{C}_{\text {of }} \mathrm{CH}_{4}$ because of multiple reasons including uncertainty in the atmospheric $\mathrm{CH}_{4}$ mole fraction scenario. Although there are many important and uncertain factors, the accurate reconstruction of the atmospheric $\mathrm{CH}_{4}$ mole fraction is particularly important, because the trend in the mole fraction can lead to significant signal in the modeled $\delta^{13} \mathrm{C}$ profile in firn due to the difference in the molecular diffusion coefficient, even in the absence of a temporal trend in atmospheric $\delta^{13} \mathrm{C}$. This study revealed a large uncertainty in the Arctic $\mathrm{CH}_{4}$ mole fraction trend over the 20th century, which supports the conclusion of Sapart et al. (2013) on the difficulty of reconstruction of the $\delta^{13} \mathrm{C}$ of atmospheric $\mathrm{CH}_{4}$ in the northern hemisphere. The NGRIP firn air samples were also analyzed for

$395 \delta^{13} \mathrm{C}$ and stable hydrogen isotope ratio $(\delta \mathrm{D})$ of $\mathrm{CH}_{4}$ (Kawamura et al., 2021), but we regrettably report that reconstruction of $\delta^{13} \mathrm{C}_{\text {of }} \mathrm{CH}_{4}$ is difficult despite our best modeling efforts (not shown).

A possibility to improve the reproducibility of the depth profile of $\mathrm{CH}_{4}$ in the NGRIP firn may come from additional constraint to the diffusivity profile along with those currently made by the six trace gases $\left(\mathrm{CO}_{2}, \mathrm{SF} 6, \mathrm{CFC}-11, \mathrm{CFC}-12, \mathrm{CFC}-113\right.$ and $\mathrm{CH}_{3} \mathrm{CCl}_{3}$ ). It could be performed by introducing additional effective tracers e.g. ${ }^{14} \mathrm{CO}_{2}$, although such measurements cannot 400 be foreseen for the NGRIP samples. This study showed that, with the currently available firn data from Greenland (NGRIP and NEEM), reliable reconstruction of the Arctic $\mathrm{CH}_{4}$ mole fraction history (independent of Antarctic records and assumed IPD) is possible back to the mid 1970s only. For the earlier period, consistent reconstruction with a small uncertainty of age estimate is currently difficult. Future sampling and measurements of ice cores at a high-accumulation site in Greenland (where age of air occluded can be determined accurately) may be the only way to reconstruct the atmospheric $\mathrm{CH}_{4}$ trend over the 20th 405 century.

\section{Data Availability}

The composition data of the NGRIP firn air samples are available on the Arctic Data archive System (ADS) of National Institute of Polar Research (https://ads.nipr.ac.jp/dataset/A20210609-001). The NEEM firn air data are available in the supplementary file of Buizert et al. (2012). Our modeling data are available upon request (umezawa.taku@nies.go.jp).

\section{Author Contribution}

TU, SS, KK and IO discussed on design of the study. KK, SA and TN conducted firn air sampling at the NGRIP site. SS, KK, TU and TS analyzed the firn air samples for trace gases. SJA set up the measurement system for the halocarbons. TU and SS made firn air model simulations. TU analyzed the measurement/modeling data and prepared the manuscript with contributions from all co-authors. 


\section{Completing interests}

The authors declare that they have no conflict of interest.

\section{Acknowledgements}

We thank Morimasa Takata at Nagaoka University of Technology for assisting the sample collection, and Jakob Schwander at University of Bern for collaboration at NGRIP. The NGRIP project was directed and organized by the Department of

420 Geophysics at the Niels Bohr Institute for Astronomy, Physics and Geophysics, University of Copenhagen. It is supported by funding agencies in Denmark (SNF), Belgium (FNRS-CFB), France (IPEV and INSU/CNRS), Germany (AWI), Iceland (RannIs), Japan (MEXT), Sweden (SPRS), Switzerland (SNF) and the USA (NSF, Office of Polar Programs). We are grateful to the efforts for the measurement and modeling data from NOAA/ESRL/GML and the NEEM firn campaign, both of which are made freely available. This work was supported by JSPS/MEXT (Japan) KAKENHI Grants-in-Aid for Young Scientists

425 B (17K18342 for TU), Grants-in-Aid for Scientific Research on Innovative Areas (17H06320 for KK) and the GRENE Arctic Climate Change Research Project (for SA).

\section{References}

Aoki, S., Nakazawa, T., Murayama, S., and Kawaguchi, S.: Measurements of atmospheric methane at the Japanese Antarctic Station. Syowa. Tellus B, 44, 273-281, https://doi.org/10.1034/j.1600- 0889.1992.t01-3-00005.x, 1992.

Blunier, T., Chappellaz, J. A., Schwander, J., Barnola, J.-M., Desperts, T., Stauffer, B., and Raynaud D.: Atmospheric methane, record from a Greenland Ice Core over the last 1000 year, Geophys. Res. Lett., 20(20), 2219-2222, https://doi.org/10.1029/93GL02414, 1993.

Buizert, C., Martinerie, P., Petrenko, V. V., Severinghaus, J. P., Trudinger, C. M., Witrant, E., Rosen, J. L., Orsi, A. J., Rubino, M., Etheridge, D. M., Steele, L. P., Hogan, C., Laube, J. C., Sturges, W. T., Levchenko, V. A., Smith, A. M., Levin, I., Conway, T. J., Dlugokencky, E. J., Lang, P. M., Kawamura, K., Jenk, T. M., White, J. W. C., Sowers, T., Schwander, J., and Blunier, T.: Gas transport in firn: multiple-tracer characterisation and model intercomparison for NEEM, Northern Greenland, Atmos. Chem. Phys., 12, 4259-4277, https://doi.org/10.5194/acp-12-4259-2012, 2012.

Chandra, N., Patra, P. K., Bisht, J. S. H., Ito, A., Umezawa, T., Saigusa, N., Morimoto, S., Aoki, S., Janssens-Maenhout, G., Fujita, R., Takigawa, M., Watanabe, S., Saitoh, N., and Canadell, J. G.: Emissions from the oil and gas sectors, coal mining and ruminant farming drive methane growth over the past three decades, J. Meteorol. Soci. Jpn., 99, https://doi.org/10.2151/jmsj.2021-015, 2021.

Dlugokencky, E. J., Houweling, S., Bruhwiler, L., Masarie, K. A., Lang, P. M., Miller, J. B., and Tans P. P.: Atmospheric methane levels off: Temporary pause or a new steady-state?, Geophys. Res. Lett., 30, 19, https://doi.org/10.1029/2003GL018126, 2003. 
Etheridge, D. M., Steel, L. O., Francey, R. J., and Langenfelds, R. L.: Atmospheric methane between 1000 A.D. and present: evidence of anthropogenic emissions and climatic variability, J. Geophys. Res., 103, 15979-15993, https://doi.org/10.1029/98JD00923, 1998.

Francey, R. J., Manning, M. R., Allison, C. E., Coram, S. A., Etheridge, D. M., Langenfelds, R. L., Lowe, D. C., and Steele, L. P.: A history of $\delta^{13} \mathrm{C}$ in atmospheric $\mathrm{CH}_{4}$ from the Cape Grim Air Archive and Antarctic firn air, J. Geophys. Res., 104(D19), 23631-23643, https://doi.org/10.1029/1999JD900357, 1999.

Fujita, R., Morimoto, S., Umezawa, T., Ishijima, K., Patra, P. K., Worthy, D. E. J., Goto, D., Aoki, S., and Nakazawa, T.: Temporal variations of the mole fraction, carbon, and hydrogen isotope ratios of atmospheric methane in the Hudson Bay Lowlands, Canada, J. Geophys. Res.: Atmos., 123, 4695-4711, https://doi.org/10.1002/2017JD027972, 2018.

Ghosh, A., Patra, P. K., Ishijima, K., Umezawa, T., Ito, A., Etheridge, D. M., Sugawara, S., Kawamura, K., Miller, J. B., Dlugokencky, E. J., Krummel, P. B., Fraser, P. J., Steele, L. P., Langenfelds, R. L., Trudinger, C. M., White, J. W. C., Vaughn, B., Saeki, T., Aoki, S., and Nakazawa, T.: Variations in global methane sources and sinks during 1910-2010, Atmos. Chem. Phys., 15, 2595-2612, https://doi.org/10.5194/acp-15-2595-2015, 2015.

Houweling, S., Dentener, F., and Lelieveld, J.: Simulation of preindustrial atmospheric methane to constrain the global source strength of natural wetlands, J. Geophys. Res., 105(D13), 17243-17255, https://doi.org/10.1029/2000JD900193, 2000.

Ishijima, K., Sugawara, S., Kawamura, K., Hashida, G., Morimoto, S., Murayama, S., Aoki, S., and Nakazawa, T.: Temporal variations of the atmospheric nitrous oxide concentration and its $\delta^{15} \mathrm{~N}$ and $\delta^{18} \mathrm{O}$ for the latter half of the 20th century reconstructed from firn air analyses, J. Geophys. Res., 112, D03305, https://doi.org/10.1029/2006JD007208, 2007.

Kawamura, K., Severinghaus, J. P., Ishidoya, S., Sugawara, S., Hashida, G., Motoyama, H., Fujii, Y., Aoki, S., and Nakazawa, T.: Convective mixing of air in firn at four polar sites, Earth Planet. Sci. Lett., 244, 3-4, 672-682, https://doi.org/10.1016/j.eps1.2006.02.017, 2006.

Kawamura, K., Umezawa, T., Sugawara, S., Ishidoya, S., Ishijima, K., Saito, T., Oyabu, I., Murayama, S., Morimoto, S., Aoki, S., and Nakazawa T.: Composition of firn air at the North Greenland Ice Core Project (NGRIP) site, Polar Data J., in press.

Landais, A., Barnola, J. M., Kawamura, K., Caillon, N., Delmotte, M., Van Ommen, T., Dreyfus, G., Jouzel, J., MassonDelmotte, V., Minster, B., Freitag, J., Leuenberger, M., Schwander, J., Huber, C., Etheridge, D., Morgan, V.: Firn-air $\delta^{15} \mathrm{~N}$ in modern polar sites and glacial-interglacial ice: a model-data mismatch during glacial periods in Antarctica? Quaternary Sci. Rev., 25, 49-62, https://doi.org/10.1016/j.quascirev.2005.06.007, 2006.

MacFarling Meure, C., Etheridge, D., Trudinger, C., Steele, P., Langenfelds, R., van Ommen, T., Smith, A., and Elkins, J.: Law Dome $\mathrm{CO}_{2}, \mathrm{CH}_{4}$ and $\mathrm{N}_{2} \mathrm{O}$ ice core records extended to 2000 years BP, Geophys. Res. Lett., 33, L14810, https://doi.org/10.1029/2006GL026152, 2006.

Martinerie, P., Nourtier-Mazauric, E., Barnola, J.-M., Sturges, W. T., Worton, D. R., Atlas, E., Gohar, L. K., Shine, K. P., and Brasseur, G. P.: Long-lived halocarbon trends and budgets from atmospheric chemistry modelling constrained with measurements in polar firn, Atmos. Chem. Phys., 9, 3911-3934, https://doi.org/10.5194/acp-9-3911-2009, 2009. 
Monteil, G., Houweling, S., Dlugockenky, E. J., Maenhout, G., Vaughn, B. H., White, J. W. C., and Röckmann, T.: Interpreting methane variations in the past two decades using measurements of $\mathrm{CH}_{4}$ mixing ratio and isotopic composition, Atmos. Chem. Phys., 11, 9141-9153, https://doi.org/10.5194/acp-11-9141-2011, 2011.

Nakazawa, T., Machida, T., Tanaka, M., Fujii, Y., Aoki, S., and Watanabe, O.: Differences of the atmospheric CH4 concentration between the Arctic and Antarctic regions in pre-industrial/pre-agricultural era, Geophys. Res. Lett., 2094320946, https://doi.org/10.1029/93GL00776, 1993.

Oyabu, I., Kawamura, K., Kitamura, K., Dallmayr, R., Kitamura, A., Sawada, C., Severinghaus, J. P., Beaudette, R., Orsi, A., Sugawara, S., Ishidaoya, S., Dahl-Jensen, D., Goto-Azuma, K., Aoki, S., Nakazawa, T.: New technique for highprecision, simultaneous measurements of $\mathrm{CH}_{4}, \mathrm{~N}_{2} \mathrm{O}$ and $\mathrm{CO}_{2}$ concentrations; isotopic and elemental ratios of $\mathrm{N}_{2}, \mathrm{O}_{2}$ and Ar; and total air content in ice cores by wet extraction, Atmos. Meas. Tech., 13(12), 6703-6731. http://doi.org/10.5194/amt-13-6703-2020, 2020.

Rhodes, R. H., Faïn, X., Stowasser, C., Blunier, T. Chappellaz, J., McConnell, J. R., Romanini, D., Mitchell, L. E., Brook, E. J.: Continuous methane measurements from a late Holocene Greenland ice core: Atmospheric and in-situ signals, Earth Planet. Sci. Lett., 368, 9-19, https:// doi.org/10.1016/j.epsl.2013.02.034, 2013.

Rice, A. L., Butenhoff, C. L., Teama, D. G., Röger, F. H., Khalil, M. A. K., and Rasmussen, R. A.: Atmospheric methane isotopic record favors fossil sources flat in 1980s and 1990s with recent increase, Proc. Natl. Acad. Sci., 113(39), 1079110796, https://doi.org/10.1073/pnas.1522923113, 2016.

Rigby, M., Montzka, S. A., Prinn, R. G., White, J. W. C., Young, D., O’Doherty, S., Lunt, M. F., Ganesan, A. L., Manning, A. J., Simmonds, P. G., Salameh, P. K., Harth, C. M., Mühle, J., Weiss, R. F., Fraser, P. J., Steele, L. P., Krummel, P. B., McCulloch, A., and Park, S.: Role of atmospheric oxidation in recent methane growth, Proc. Natl. Acad. Sci., 114(21), 5373-5377. https://doi.org/10.1073/pnas.1616426114, 2017.

Rommelaere, V., Arnaud, L., and Barnola, J.-M.: Reconstructing recent atmospheric trace gas concentrations from polar firn and bubbly ice data by inverse methods, J. Geophys. Res., 102(D25), 30069-30083, https://doi.org/10.1029/97JD02653, 1997.

Saito, T., Yokouchi, Y., Aoki, S., Nakazawa, T., Fujii, Y., and Watanabe, O.: A method for determination of methyl chloride concentration in air trapped in ice cores, Chemosphere, 63(7), 1209-1213, https://doi.org/10.1016/j.chemosphere.2005.08.075, 2006.

Sapart, C. J., Monteil, G., Prokopiou, M., van de Wal, R. S. W., Kaplan, J. O., Sperlich, P., Krumhardt, K. M., van der Veen, C., Houweling, S., Krol, M. C., Blunier, T., Sowers, T., Martinerie, P., Witrant, E., Dahl-Jensen, D., and Röckmann, T.: Natural and anthropogenic variations in methane sources during the past 2 millennia, Nature, 490, 85-88, https://doi.org/10.1038/nature11461, 2012.

510 Sapart, C. J., Martinerie, P., Witrant, E., Chappellaz, J., van de Wal, R. S. W., Sperlich, P., van der Veen, C., Bernard, S., Sturges, W. T., Blunier, T., Schwander, J., Etheridge, D., and Röckmann, T.: Can the carbon isotopic composition of 
methane be reconstructed from multi-site firn air measurements? Atmos. Chem. Phys., 13, 6993-7005, https://doi.org/10.5194/acp-13-6993-2013, 2013.

Saunois, M., Stavert, A. R., Poulter, B., Bousquet, P., Canadell, J. G., Jackson, R. B., Raymond, P. A., Dlugokencky, E. J., Houweling, S., Patra, P. K., Ciais, P., Arora, V. K., Bastviken, D., Bergamaschi, P., Blake, D. R., Brailsford, G., Bruhwiler, L., Carlson, K. M., Carrol, M., Castaldi, S., Chandra, N., Crevoisier, C., Crill, P. M., Covey, K., Curry, C. L., Etiope, G., Frankenberg, C., Gedney, N., Hegglin, M. I., Höglund-Isaksson, L., Hugelius, G., Ishizawa, M., Ito, A., Janssens-Maenhout, G., Jensen, K. M., Joos, F., Kleinen, T., Krummel, P. B., Langenfelds, R. L., Laruelle, G. G., Liu, L., Machida, T., Maksyutov, S., McDonald, K. C., McNorton, J., Miller, P. A., Melton, J. R., Morino, I., Müller, J., Murguia-Flores, F., Naik, V., Niwa, Y., Noce, S., O'Doherty, S., Parker, R. J., Peng, C., Peng, S., Peters, G. P., Prigent, C., Prinn, R., Ramonet, M., Regnier, P., Riley, W. J., Rosentreter, J. A., Segers, A., Simpson, I. J., Shi, H., Smith, S. J., Steele, L. P., Thornton, B. F., Tian, H., Tohjima, Y., Tubiello, F. N., Tsuruta, A., Viovy, N., Voulgarakis, A., Weber, T. S., van Weele, M., van der Werf, G. R., Weiss, R. F., Worthy, D., Wunch, D., Yin, Y., Yoshida, Y., Zhang, W., Zhang, Z., Zhao, Y., Zheng, B., Zhu, Q., Zhu, Q., and Zhuang, Q.: The Global Methane Budget 2000-2017, Earth Syst. Sci. Data, 12, 1561-1623, https://doi.org/10.5194/essd-12-1561-2020, 2020.

Schwander, J.: The transformation of snow to ice and the occlusion of gases. In: The Environmental Record in Glaciers and Ice Sheets (eds. H. Oeschger and C. C. Lang- way), John Wiley \& Sons, Berlin 53-67, 1989.

Schwander, J., Barnola, J.-M., Andrié, C., Leuenberger, M., Ludin, A., Raynaud, D., and Stauffer, B.: The age of the air in the firn and the ice at Summit, Greenland, J. Geophys. Res., 98(D2), 2831-2838, https://doi.org/10.1029/92JD02383, 1993.

Severinghaus, J. P., Albert, M. R., Courville, Z. R., Fahnestock, M. A., Kawamura, K., Montzka, S. A., Mühle, J., Scambos, T. A., Shields, E., Shuman, C. A., Suwa, M., Tans, P., and Weiss, R. F.: Deep air convection in the firn at a zeroaccumulation site, central Antarctica, Earth Planet. Sci. Lett., 293, 359-367, https://doi.org/10.1016/j.epsl.2010.03.003, 2010.

Sowers, T., Bender, M., Raynaud, D., and Korotkevich, Y. S.: $\delta^{15} \mathrm{~N}$ of $\mathrm{N}_{2}$ in air trapped in polar ice: A tracer of gas transport in the firn and a possible constraint on ice age-gas age differences, J. Geophys. Res., 97(D14), 15683-15697, https://doi.org/10.1029/92JD01297, 1992.

Stern, D. I., and Kaufmann, R. K.: Estimates of global anthropogenic methane emissions 1860-1993, Chemosphere, 33, 1, 159-176, https://doi.org/10.1016/0045-6535(96)00157-9, 1996.

Sturrock, G. A., Etheridge, D. M., Trudinger, C. M., Fraser, P. J., and Smith, A. M.: Atmospheric histories of halocarbons from analysis of Antarctic firn air: Major Montreal Protocol species, J. Geophys. Res.-Atmos., 107, 4765, https://doi.org/10.1029/2002JD002548, 2002.

Sugawara, S., Kawamura, K., Aoki, S., Nakazawa, T., and Hashida, G.: Reconstruction of past variations of $\delta^{13} \mathrm{C}$ in atmospheric $\mathrm{CO}_{2}$ from its vertical distribution observed in the firn at Dome Fuji, Antarctica, Tellus, Ser. B, 55, 159-169, https://doi.org/10.1034/j.1600-0889.2003.00023.x, 2003, 
545 Sugawara, S., Ishidoya, S., Aoki, S., Morimoto, S., Nakazawa, T., Toyoda, S., Inai, Y., Hasebe, F., Ikeda, C., Honda, H., Goto, D., and Putri, F. A.: Age and gravitational separation of the stratospheric air over Indonesia, Atmos. Chem. Phys., 18, 1819-1833, https://doi.org/10.5194/acp-18-1819-2018, 2018.

Trudinger, C. M., Enting, I. G., Etheridge, D. M., Francey, R. J., Levchenko, V. A., Steele, L. P., Raynaud, D. and Arnaud, L.: Modeling air movement and bubble trapping in firn, J. Geophys. Res. 102, 6747-6763, https://doi.org/10.1029/96JD03382, 1997.

Trudinger, C. M., Etheridge, D. M., Rayner, P. J., Enting, I. G., Sturrock, G. A., and Langenfelds, R. L.: Reconstructing atmospheric histories from measurements of air composition in firn, J. Geophys. Res., 107(D24), 4780, https://doi.org/10.1029/2002JD002545, 2002.

Trudinger, C. M., Enting, I. G., Rayner, P. J., Etheridge, D. M., Buizert, C., Rubino, M., Krummel, P. B., and Blunier, T.: How well do different tracers constrain the firn diffusivity profile? Atmos. Chem. Phys., 13, 1485-1510, https://doi.org/10.5194/acp-13-1485-2013, 2013.

Umezawa, T., Goto, D., Aoki, S., Ishijima, K., Patra, P. K., Sugawara, S., Morimoto, S., and Nakazawa, T.: Variations of tropospheric methane over Japan during 1988-2010, Tellus B, 66, 23837, http://dx.doi.org/10.3402/tellusb.v66.23837, 2014.

van Aardenne, J. A., Dentener, F. J., Olivier, J. G. J., Goldewijk, C. G. M. K., and Lelieveld, J.: A $1^{\circ} \times 1^{\circ}$ resolution data set of historical anthropogenic trace gas emissions for the period 1890-1990, Global Biogeochem. Cycles, 15(4), 909-928, https://doi.org/10.1029/2000GB001265, 2001.

Witrant, E., Martinerie, P., Hogan, C., Laube, J. C., Kawamura, K., Capron, E., Montzka, S. A., Dlugokencky, E. J., Etheridge, D., Blunier, T., and Sturges, W. T.: A new multi-gas constrained model of trace gas non-homogeneous transport in firn: evaluation and behaviour at eleven polar sites, Atmos. Chem. Phys., 12, 11465-11483, https://doi.org/10.5194/acp-1211465-2012, 2012. 